\title{
Interpretation of Humor between Chinese and Americans from the Angle of Culture in Friends
}

\author{
Jing Dai \\ Zhejiang Ocean University, Zhoushan, China \\ Qi'ang Liu \\ Foreign Language College, Zhejiang Ocean University, China
}

\begin{abstract}
Humor is a kind of language art that permeates every corner of people's life. It can relieve pressure, regulate atmosphere and it is an important tool for interpersonal communication. However, due to different cultures, interpretation of humor between Chinese and Americans has their own characteristics. In recent years, researches on humor have mainly been done from the psychological and sociological perspectives. In the guidance of Nida's classification of culture, this thesis makes a contrastive study of interpretation of humor between Chinese and Americans by analyzing the fragments of humor in Friends. It aims at helping to interpret different humors between Chinese and Americans, thus promoting cultural exchanges and interpersonal communication.
\end{abstract}

Index Terms - interpretation of humor, Chinese, Americans, Friends

\section{LANGuage, Culture AND Humor}

Humor is a kind of verbal art, which permeates almost every corner of people's life. A sense of humor is a person's ability (Tan, 1997). It plays an inestimable role in social life with a unique artistic sense, especially in interpersonal communication. The significance of humor can be seen: It adds much happiness and pleasure to life and promotes positive attitudes towards life. Furthermore, it helps people out of trouble in communication.

However, humors are diverse and have their own unique cultural characteristics. Obstacles in interpreting humor between Chinese and Americans can be easily noticed because people lack cultural knowledge which is involved. Owing to the universality and diversity of culture, it is difficult to interpret and get humor when the content is connected with culture. Meanwhile, people are apt to treat things in their own stereotyped thinking or views.

There are many obstacles when people from different cultures interpret humor, so it's necessary to probe into interpretation of humor between Chinese and Americans. Here are the main purposes of this thesis. Firstly, it is expected to help readers establish an awareness of cultural differences in interpretation of humor. Secondly, some proposals are put forward to avoid embarrassments in intercultural communication when concerning humor. It is conducive to facilitate communication from people to people and culture to culture.

Language, culture and humor are three critical objects of study in this thesis. Language is a purely human and non-instinctive method of communicating ideas, emotions and desires by means of voluntarily produced symbols (Sapir, 1921). Culture, broadly speaking, means the total way of life of people, including the patterns of belief, customs, objects, institutions, techniques, and language that characterizes the life of human community (Dai \& He, 2002). Humor is a spiritual phenomenon that appeals to sensible fun $(\mathrm{Hu}, 1987)$. They are closely related with and inseparable from each other. At the same time, language is, in general, the primary vehicle of acculturation, of learning one's culture (Schiffman, 2002). Every language is a part of culture and it serves and reflects cultural needs (Dai \& He, 2002). It is used to sustain and convey culture and cultural ties. Different ideas spring from different language use within one's culture. Language is not only closely related to culture, but also has an intimate relationship with humor. It is an output both verbal and physical. Due to this characteristic, language is a significant carrier and the medium of expressing humor. Humor adheres to language, and its existence without language is hard to imagine. The relationship between humor and culture is quite tacit. Humor demonstrates the accumulation of a nation's culture. Furthermore, it is a production in civilization era, also a representation of highly developed culture. Owing to the diversity of culture, humor also behaves in a various and abundant way. Since culture is a very broad term, it is difficult to define culture accurately or precisely. There are various visions of the definition and classification of culture. But Eugene A. Nida's specific classification of culture is believed to have a more feasible guiding significance to this thesis. Nida, an American translator, divides culture into ecological culture, linguistic culture, religious culture, material culture and social culture (Nida, 1993).

Ecological culture focuses on values, the spiritual power to balance human society and nature.

It solidifies in the form of culture and inherits excellent results of human cognition of nature and transformation of nature. Linguistic culture refers to the study of all language sets. Linguistic culture mentioned in this thesis especially refers to a linguistic phenomenon: idioms. Religion is a special cultural phenomenon in the development of human society, and is firmly embedded in culture (Loewenthal, 2007). It is a kind of ideological belief of a particular form, and it 
is also a universal cultural phenomenon, inclusive of rich cultural connotations. It affects people's ideology, living customs and so on. Material culture is, chiefly, something portable and perceptible by touch and therefore has a physical, material existence that is a component of human cultural practice. It also includes things which are perceptible by sight (Woodward, 2007). Social culture refers to the total amount of material wealth and spiritual wealth created by mankind in the course of human social and historical practice. It has the characteristics of region, nationality or group, the general term of various cultural phenomena and cultural activities that exert a wide influence on social groups.

\section{DifFERENT SENSE OF HumOR BETWEen CHINESE AND AMERICANS}

In different cultures, sense of humor differs from each other. China is located in the hinterland. Its feudal society is longer than that of any other country in the west, which has shaped the Chinese characters of self-control, introspection, humility, and patience. Confucianism emphasizes virtue and ethical concept. China's traditional education highlights family and country, sacrificing individual interests for public benefits. To a certain extent, all these influence modern Chinese people's sense of humor. Chinese humor emphasizes more on morality as well as on social education. Humor is always used to satire or preach or facilitate social harmony.

Example 1:

Guo: Is there a lobster 2 feet long?

Yu: Sir, wait for a moment please, and I will reply to you later. I'm sorry, sir, there is only a lobster 2.2 feet long.

Guo: Hum! What a broken restaurant it is, not even having a 2-foot-long lobster. Give me a dish of shredded potatoes! (from I Want to be Happy)

This dialogue is a crosstalk. In fact, the protagonist Guo can't afford the lobster. However, he orders a big lobster deliberately pretending to be wealthy. Though there is a much bigger lobster, he complains that the restaurant can't serve him a 2-foot-long lobster. It is an irony used by Guo who cannot afford to eat the lobster but purposely makes difficulties for $\mathrm{Yu}$ only to maintain his own face. On this occasion, humor is closely connected with face culture. The irony used in the dialogue is not only to create a humorous atmosphere but also to provide social education, suggesting that people should not care about their face excessively. Chinese people are apt to combine sarcasm with humor. Likewise, they are good at using irony which has both the effect of humor and the function of preaching.

America is located in coastal areas, and the adventurous spirit has become an important part of the American traditional spirit. It facilitates the formation of their open and bold personality. American religious traditions emphasize enterprise and affirm personal value, which makes individualism obvious. The idea of equality of all people becomes prevailingly accepted. Whether he be the president or God, he is equal to the ordinary people. The life of ordinary people can be the material of humor, with no exception to the God. Generally speaking, different from Chinese humor, American humor plays its role in relieving mental stress and establishing superiority. Just as Freud said, humor was the release of latent emotional energy (Gong, 1991). The topics of American humor are much wider than those of Chinese humor.

Example 2:

Mother (in a low voice): Tommy, your grandfather is very sick. Can't you say something nice to cheer him up a bit.

Tommy: Grandfather, would not you like to have soldiers at your funeral?

(from Humorous story selection)

This dialogue shows a good presentation of American humor. Tommy wants to cheer his grandfather up a bit. He uses grandfather's funeral to create humor. In American culture, a funeral is more ceremonious if soldiers can attend. It reflects the style of American humor, focusing on the effect of humor not the content of humor. They use humor to take pleasure in themselves or people around them. Compared with Chinese humor, American humor has a wider range of topics. It stresses the function of humor to relieve mental stress.

The role of humor in people's life can't be underestimated. Humor is one of the most interesting, infectious and universal language art. It ennobles people's spirits and extends their love to others (Streiker, 1998). Humorous language can make social atmosphere relaxing and harmonious, which facilitates communication. When the content of humor involves culture, it becomes difficult to interpret. Hence, failure to interpret humor is frequently seen in daily communication. Moreover, failure to interpret humor will bring lots of inconvenience. In some cases, it can even make trouble. When having instant exchange of information, people need to make a response in a short time. On this occasion, failure to interpret humor can be detrimental. On one hand, conversation is hard to continue or it will proceed in a direction which is not anticipated. On the other hand, people may be regarded as indifferent and not friendly at all. Once it happens, it is tough to make up for it. The inconvenience still exists when there is no instant exchange of information. It can be seen while people are reading, watching videos, etc.. Though there is no bilingual communication, it has a major impact on us. Not interpreting humor in an appropriate way, people will fail to acquire the correct information others send or their real intention.

\section{HUMOR REPRESENTED IN FRIENDS}

Friends is an American sitcom directed by David Crane and Marta Kauffman, which was aired on NBC from September 22, 1994 to May 6, 2004. It consists of 236 episodes of 10 seasons. It has been watched by 52.5 million American viewers. The series has won many awards and was nominated 63 Primetime Emmy Awards (Liu, 2011). 
Friends is a long-running American television situation comedy, centering on the lives of six twenty-somethings (eventually thirty-somethings) (three males, three females) who share neighboring apartments in Manhattan (Zhou, 2005). It fully describes their life, laughters, troubles, friendship, love, contradictions and work. The friendship and affection are greatly cherished by them. They trust and encourage each other. It is their positive and optimistic attitude to life that encourages millions of people in the world. Positive reviews are received throughout the world. Friends becomes one of the most popular sitcoms of all time.

With its popularity, more people start to know American culture.

As a milestone of the American sitcom, Friends is full of intellectual and cultural art. Relying on ingenious plot structures, humorous characters and exaggerated expressions, it shows American humor vividly. Humor concerning cultural factors can be easily found in their talks and conversations. As for foreign audience, this is the most difficult to interpret, since lots of non-native culture is absent in their minds.

\section{A. Humor with Ecological Culture}

Many philosophers, sociologists, anthropologists, historians and linguists have been trying to define and classify culture from the perspective of respective disciplines. It is believed that Nida's specific classification of culture has a more feasible guiding significance to this thesis. Dialogues extracted from the aspect of ecological culture, linguistic culture, religious culture, material culture and social culture are to be analyzed.

Ecological culture is a kind of spiritual power to balance human society and nature. It is also a deduction and expression of the relationship between human and nature, which occurs and develops in certain regions. There are differences in the natural ecosystem of different regions. It naturally produces the ideological consciousness with regional environmental characteristics and creates an ecological culture with regional characteristics. In Friends, ecological culture, an indispensable part of culture, plays an important role in creating humor and bringing happiness to the audience.

Example 3:

[Scene: at Monica's, Rachel just got out of the wedding.]

Ross: So Rachel, What're you, uh... What're you up to tonight?

Rachel: Well, I was kinda supposed to be headed for Aruba on my honeymoon, so nothing!

Ross: Right, you're not even getting your honeymoon, God... No, no, although, Aruba, this time of year... talk about your... big lizards.

(from Season1 Episode1)

Aruba is a Caribbean island surrounded by sea. Influenced by the trade winds of the Atlantic, it has a tropical, oceanic climate. Temperature there keeps at around $28 \mathrm{C}$ all year around. There are many tropical animals on the island, such as lizards, tropical rattlesnakes, red-tailed tropical birds and so on. The pleasant temperature and beautiful scenery make Aruba's tourism industry thrilling. A large number of tourists flood to Aruba for a holiday every year.

Ross firstly says Rachel can't even spend her honeymoon. That's a brutal truth. But Ross realizes he should have said it diplomatically. Then he tries to be sad, wanting to show his sympathy to Rachel. Americans think that Ross is going to say something to comfort Rachel. However, 'big lizards', unexpected words just make them burst into laughters. To interpret humor in this dialogue, the critical part is to know the knowledge of ecological culture, Aruba and big lizards. Humor here can be easily caught by Americans. Nevertheless, it is difficult for Chinese audience to get it. The main reasons are as follows. Aruba and big lizards involve the knowledge of ecological culture, which Chinese audience are short of. They can't get the relationship between the big lizards and Aruba. What they know is the literal meaning of the two words. Undoubtedly failure to catch the humorous point may occur.

\section{B. Humor with Linguistic Culture}

In this thesis, linguistic culture especially refers to a linguistic phenomenon: idioms. As the name implies, idioms are namely habitual expressions. They are linguistic chunks consisting of fixed phrases and short languages which have unique cultural features and connotations. A good mastery of connotations of English idioms is helpful for Chinese audience to interpret humor in Friends.

In general, English idioms have their own distinct semantic features. They cannot be arbitrarily added or deleted or replaced, especially in written English or formal situations. For example, "kick the bucket" can't be changed into "kick the big bucket" or "kick bucket" or "kick the pail". However, spoken English is more flexible, and people want to have a more relaxing atmosphere when talking with their friends. In order to add a humor flavor to language, they sometimes deliberately create some idioms.

Example 4:

[Scene: Monica and Rachel's, Rachel, Monica, and Phoebe are there.]

Rachel: Can you believe what a jerk Ross was being?

Monica: Yeah, I know. He can get really competitive.

Phoebe: Ha. Ha, ha.

Monica: What?

Phoebe: Oh, hello, kettle? This is Monica. You're black.

Monica: Please! I am not as bad as Ross. 
(from Season1 Episode18)

In this scene, friends are playing poker together. Girls often lose, especially Rachel. She is dissatisfied with Ross's behavior in playing poker. Monica also believes Ross is competitive. But as audience who have seen Friends know, one of Monica's characters is competitiveness. So it means that a competitive person is complaining about another person's competitiveness. When Paul laughs at it, the audience guess she may directly say Monica is also competitive. Nevertheless, Phoebe pretends to make a telephone call, "Oh, hello, kettle? This is Monica. You are black".

American people will find that the expression is an idiom variant, deriving from an idiom --- "It's like the pot calling the kettle black". Originally, it is a response often given when someone criticizes another for a fault they also "the pot calling the kettle black" have themselves. The American audience soon realize that "pot" is used to allude to Monica and Phoebe cleverly uses Ross and competitiveness to replace kettle and black. They get the humor quickly and precisely. But it is hard for most Chinese audience to get it. First, the idiom is not familiar to Chinese audience. There are so many English idioms that even native speakers and advanced English learners find impossible to know them all. Furthermore, the sentence here is an idiom variant, which makes it more challenging for Chinese audience to interpret the humor. Chinese audience are always accustomed to focusing on the subtitle translation when watching Friends. One of its harmful effects is that they may interpret the main plot at that moment but forget it soon. As a result, it is not conductive for them to have a good mastery and interpretation of the characters.

\section{Humor with Religious Culture}

The United States is a multi-religious country, and almost everyone has his religious belief. About $80 \%$ of Americans are Christians, which determines the role of Christianity in American culture. Many English humorous words are related to it to some extent. Only $8 \%$ of U.S. citizens are non-religious (Joas, 2009).

Example 5:

[Scene: at Monica and Rachel's]

......

Joey: Hold it, hold it. I gotta side with Chandler on this one. When I first moved to the city, I went out a couple of times with this girl, really hot, great kisser, but she had the biggest Adam's apple. It made me nuts.

Chandler: (to Ross) You or me?

Ross: I got it. Uh, Joey, women don't have Adam's apples.

Joey: You guys are messing with me, right?

All: Yeah.

(from Season 2 Episode 3)

“Adam's apple" here is allusion from the Bible Story, referring to male's laryngeal prominence. According to Genesis of the Old Testament, Adam and Eve were the ancestors of human beings. God built a garden in Eden for them to live a carefree life. In the garden, there was a tree with many desirable fruits: apples. God told them that they could not eat the fruit because it was a "forbidden fruit". However, giving in to the temptation of the snake, they ate the forbidden fruit. Just as they were enjoying the delicious apple, God found it. Frightened, Adam ate it in a hurry, and a piece of apple flesh stuck in his throat, leaving a lump, called "Adam's apple": laryngeal prominence.

In America, most people are familiar with this story which is from the Bible. They know Eve", "Adam", "Eden" and "forbidden fruit", of course laryngeal prominence, which only males have. Joey's utterances that females have laryngeal prominence deviate from people's presupposition. It is obvious that Joey knows nothing about the story. Joey's words show his ignorance. It is just his silly words and his ignorant image makes them laugh. Nevertheless, Chinese audience who does not know the story can hardly feel the humor in this dialogue. Some Chinese may know "Eve", "Adam" and "Eden", but most of them only have simple understanding of the story. Their interpretation of religious culture is not in-depth. Religious culture itself has a long history and profound cultural heritage is conserved through history. From architecture to diet, from religious beliefs to variety of religious activities, it can be seen that religious culture has a wide scope. They all increase the difficulties of interpreting American religious culture for Chinese people. When humor involves religious culture, it is easy for Chinese to feel at a loss.

\section{Humor with Material Culture}

Material culture mainly refers to the material products created by human beings. It includes production tools, labor objects and the technology to create material products. These items not only reflect the way people live, but also affect people's attitude to life. They have a rich cultural significance, and are often reflected in verbal communication.

Example 6:

[Scene: at Rachel and Joey's, Rachel, Joey, Monica and Phoebe are there. Thanksgiving Day is coming.]

Monica: Just so you know, I'm not gonna make a turkey this year.

Joey: What?

Monica: Phoebe does not eat Turkey.

Joey: Phoebe!

Phoebe: Turkeys are beautiful, intelligent animals.

Joey: They are not. They are ugly and stupid and delicious. 


\section{(from Season 8 Episode 9)}

In the United States, roasted turkey is a must for Thanksgiving Day. With fierce competition in their work, people have a fast pace and a simple diet in daily life. However, it's different on Thanksgiving night. On that night, families will have dinner together, and the main food is roasted Turkey. So, Thanksgiving is also called "Turkey day". In this conversation, Phoebe chooses not to eat turkey with his ridiculous reason "Turkeys are beautiful and smart". It is strongly opposed by Joey, creating a funny effect. Absolutely, Turkey is not unfamiliar to Americans. The humor is quite easy for them to interpret. However, the humor can be tough for Chinese to interpret. Even though many Chinese people know the importance of turkey to Americans, they may still feel confused about the dialogue between Phoebe and Joey. They will wonder if turkey is beautiful or ugly, intelligent or stupid. They don't know that's a ridiculous reason of Joey and can't interpret humor in the dialogue. The turkey is common and crucial to Americans. Chinese people are inclined to produce inertial thinking that everyone in America should like eating turkey. They tend to think so because they take it for granted that Americans like turkey very much.

\section{E. Humor with Social Culture}

Social culture exerts a wide influence on social groups. It covers people's different ways of life in different societies. In Friends, a large number of utterances and expressions are related to famous brand, movies, literature, history, music and so on. They are all different aspects of social culture.

Example 7:

Music:

[Scene: Sting's Apartment, Phoebe has come to talk about Jack and is waiting for Sting's wife, Trudie Styler, to enter.]

Trudie Styler: Are you here for tickets?

Phoebe: Oh, thank you. Four would be great.

Trudie Styler: I'm not giving concert tickets to someone who'd use their son like this!

Phoebe: Oh good! Then you're in luck! Ben's not my son!

Trudie Styler: (stands up) Look, I've just pressed a button, triggering a silent alarm. Any minute now, the police will be here!

Phoebe: The Police? Here? A reunion?! (She gets out her camera.)

(from Season 8, Episode 10)

Sting is a leader singer in America. He also has a famous band "the Police". Although the band has left the stage, Sting still adheres to his musical career. Furthermore, he is recently preparing for his new concert. Phoebe is a big fan of Sting, but now she is upset about not getting tickets for his concert. She is surprised to find out that Sting's son and Ross's son are classmates. Ben is Ross's son. Hence, she just comes to Sting's home for tickets by pretending to be Ben's mom. However, she fails and Sting's wife wants to call police to drive her out. But as a big fan of Sting, Phoebe's first reaction to "the Police" is to take out the camera and naively thinks she will see the band again.

Being acquainted with Sting and his band, Americans can easily interpret this dialogue and get humor. It is because they have the basic information of material culture. However, the humor is hard for Chinese audience. When Chinese audience see the word "the Police", they may just think of the police officers, policeman and so on. They have no idea that "the Police" is a name of Sting's band. The material culture of the United States develops rapidly. Chinese people can't immediately follow the speed of the updating material culture.

\section{PROPOSALS FOR REMOVING OBSTACLES TO HUMOR INTERPRETATION}

Through the analysis of the above episodes extracted from Friends, the characteristics of five American cultures are generally revealed. Considering Chinese people's difficulties in interpreting American humor, a few proposals are made, to lessen the chances of misunderstanding, to strengthen their sensitivity to cross-cultural differences and awaken their cultural consciousness.

\section{A. Increase of Cultural Input}

Judging from the above analysis, it is concluded that it is difficult for Chinese to interpret American humor when it involves culture. Increasing cultural input not only helps people to interpret more about American culture, but also encourages their humor output because there is no output without enough input. There are various ways to increase cultural input. Watching classic comedies is a kind of useful input. American culture is well embodied in these classic comedies, like Friends, The Big Bang Theory, etc. By watching classic comedies, Chinese people can have a better interpretation of American culture and their humor. Thus they have chance to share humor with others. Likewise, reading newspapers, perusing literature and knowing something about the Bible are beneficial. The Bible is an abundant source of numerous idioms, religious stories and their customs. It is safe to say that you are learning culture when reading the Bible. Apart from this, since religious culture is an essential part, it is critical for Chinese to gain religious knowledge through a variety of ways.

\section{B. Decrease of Inertial Thinking}


Inertial thinking is a great obstacle for Chinese to interpret American humor. Inertial thinking hinders Chinese from correctly interpreting American humor. It's not easy for most people to avoid inertial thinking because they are inclined to treat things in their own stereotyped thinking naturally. Past experience or gained knowledge is helpful, but they are not appropriate for everything. When thinking or judging, they should learn to think from multiple angles. It is suggested that cross-cultural education should be done when people are in their early ages. An influence and indoctrinization of fixed and stereotyped thinking in this period will make a premature formation of people's brain cells and thus hold back the development of creative thinking capability. Such fixed thinking habits as customs and conventions gradually influence the cross-cultural consciousness. It is essential to try to decrease inertial thinking in people's mind.

\section{CONCLUSiON}

All in all, it is found that the sense of humor between Chinese and Americans is really different. The Chinese humor emphasizes more on morality, social education etc. They tend to use humor to satire or preach or facilitate social harmony. The topics of humor are more restrictive than American humor. Compared with Chinese, Americans use humor to relieve their mental anxiety or to establish. It is further discovered that failure to interpret humor will bring lots of inconvenience in communication. By analyzing some episodes in Friends, it can be seen, to some extent, people's failure to interpret humor is closely relevant to their cultural consciousness. Culture involves a wide range of factors and accumulates constantly through the long history, and culture may develop quickly, like material culture, which makes it quite difficult for foreigners to follow and understand.

Due to the wide range of cultural factors and the difficulty in classifying it, this thesis does not contain many other perspectives. The number of extracted episodes is limited, and the analysis may not be complete or perfect enough. It is expected that further study on this thesis can be continued and the theoretical research is hoped to put into practice one day.

\section{REFERENCES}

[1] Cheng Chunbo. (1983). Humorous Story Selection. Hebei: Hebei People Press.

[2] Dai Weidong \& He Zhaoxiong. (2002). A New Concise Course in Linguistics for Students of English. Shanghai: Shanghai Foreign Languages Education Press.

[3] Eugene A. Nida. (1993). Language, culture, and translating. Shanghai: Shanghai Foreign Language Education Press.

[4] Gong Weicai. (1991). The Language Art of Humor. Chongqing: Chongqing Press.

[5] Hans Joas. (2009). The Religious Situation in the United States. In B. Stiftung (Ed.), What the world believes: Analysis and commentary on the religion monitor 2008 (pp. 317-334).

[6] Harold F. Schiffman. (2002). Linguistic Culture and Language Policy. London: New York: Routledge.

[7] Hu Fanchou. (1987). Humorous Linguistics. Shanghai: Shanghai Academy of Social Sciences Press.

[8] Ian Woodward. (2007). Understanding Material Culture. London: SAGE Publications.

[9] Kate Loewenthal. (2007). Religion, culture and mental health. New York: Cambridge University Press, 14 (1): 1-8.

[10] Lowell D. Streiker. (1998). An Encyclopedia of Humor. the United States: Hendrickson Publishers.

[11] Liu Bo. (2011). An Analysis of Sino-American Cultural Differences in Friends. Henan University of Economics and Law in.

[12] Sapir. E. (1921). Language: An Introduction to Study of Speech. NewYork: Harhcount, Brance \& Company.

[13] Tan Daren. (1997). Humor and Verbal Humor. Beijing: Joint Publishing.

[14] Zhou Xiaoli. (2005). Humor analysis in the American sitcom Friends: analysis of discourse analysis. Central China Normal University.

Jing Dai was born in Ninghai, China in 1997. She is a junior of Foreign Language College, Zhejiang Ocean University, majoring in English Teaching.

Qi'ang Liu was born in Zhoushan, China in 1978. She is a Master of Arts in Literature and Language of Zhejiang Normal University, China in 2009.

She is currently an Associate Professor of Foreign Language College, Zhejiang Ocean University, China. Her research areas are in English Teaching and Scientific Research. 